\title{
Treatment of Inappropriate Sinus Tachycardia: Still A Long Way To Go
}

\author{
Riccardo Cappato ${ }^{1}$ \\ ${ }^{1}$ IRCCS- MultiMedica Group
}

February 1, 2021

Hosted file

JCE IST Editorial to Shabtaie et al. IST 1.1 pre-final.pdf available at https://authorea.com/ users/393139/articles/506823-treatment-of-inappropriate-sinus-tachycardia-still-a-longway-to-go 